\title{
The Dark Side of Information Technology Introduction to the 2018 Minitrack
}

\author{
Ofir Turel \\ California State University, \\ Fullerton \\ oturel@,fullerton.edu
}

\author{
Amr Soror \\ California State University, \\ Fullerton \\ oturel@fullerton.edu
}

\author{
Zach Steelman \\ University of Arkansas \\ zteelman@walton.uark.edu
}

Over the last several years, researchers and practitioners have started noticing the emergence of several unplanned, often negative, consequences of information technology (IT) use at the workplace and at home. This represent a slight shift in the attention pendulum of IS researchers: from almost entirely focusing on the positive aspects and benefits of IT use (which are indeed, many), to some attention to what we call "the dark side of IT", or the negative effects of IT on people, firms and societies. As such, the literature has started to present a more balanced view of the effects of IT on individuals, employees, firms and societies, as it should $[1,2]$.

This minitrack represents an academic attempt to extend the accumulated body of knowledge regarding dark-side of IT use issues. It does so by creating both horizontal and vertical extensions. Horizontal extensions refer to the deepening of our understanding of dark side phenomena that have been already explored. Such phenomena include, but are not limited to, IT addiction [3-5], false representation on social media [6], technology-family conflict [7], sleep deprivation due to IT use [8], IT-mediated interpersonal deviance [9], organizational deviance via social networking site use [10], swearing online [11], using distracting technologies while driving [12], time distortion during IT use [13], and many others.

Vertical extensions refer to plowing new grounds or focusing on qualitatively new or different phenomena, which has not been explored before. Given the pace of changes in IT and IT use patterns (just consider issues such as fake news, social media influence on election results, physical injuries during location-based augmented reality games, such as Pokemon Go, and cyber-bullying, that did not exist or at least did not receive much attention several years ago), it is conceivable to expect more, often unforeseen, vertical extensions related to the "dark side of IT use".

The studies in this minitrack do both: some provide vertical and other horizontal extensions of the extant literature. The first paper in Session 1 of the minitrack,
"Consequences of Discontinuing Knowledge Work Automation - Surfacing of Deskilling Effects and Methods of Recovery" examines how IT can lead to deskilling of employees, and consequently, how deskilled employees cope with the discontinuance of the IT that did parts of the task for them. The deskilling of employees via IT adoption and use and coping with reversing the situation are interesting new phenomena that merit further research. This is an example of a vertical extension of the broadening stream of research on the dark side of It use.

The second paper in Session 1 of the minitrack, "How Do You Handle It? An Investigation of Facebook Affordances and Envy" proposes a horizontal extension of the emergent literature on envy on social networking sites. It uses a literature review to theorize on the effect of key social media affordances (similarity, closeness, domain relevance, control and justification) on situational envy on social media; it also suggests that such envy could lead to differential real-life and social-media responses.

The third paper in Session 1 of the minitrack, " Do You Plead Connected?" - Understanding How Lawyers Deal With Constant Connectivity" performs a Q methodological study among Swiss and Austrian employees to explore the strategies they employ for dealing with constant connectivity. They observe four user types, each of which employs primarily different coping strategies. These profiles are linked to attributes of the work environment, the hierarchical position of the employee, the perceived autonomy he or she has and his or her personality. Excess connectivity at the work place represents a horizontal extension of the literatures on distraction, stress and information overload.

The first paper in Session 2 of the minitrack, "Personality Predictors of IT Addiction" provides a horizontal extension of the body of work on IT addiction. It leverages the five-factor model of personality and examines how neuroticism, conscientiousness, and agreeableness predict addiction to social networking site use and how neuroticism 
moderated the conscientiousness effect, and how conscientiousness moderates the agreeableness effect. It hence portrays a more complex relationship between personality and IT addiction, than previously assumed.

The second paper in Session 2 of the minitrack, "Investigating Malware Epidemiology and Child Exploitation Using Algorithmic Ethnography" uses ethnographic techniques to explore a relatively underexamined phenomenon, namely child exploitation as mediated via technology (a vertical extension of mainstream IS research) and its relation to malware (a horizontal extension of an existing body of work). The findings document links between child exploitation materials and high-risk malware-containing ads.

\section{References}

[1] M. Tarafdar, J. D'Arcy, O. Turel, and A. Gupta, "The dark side of information technology," MIT Sloan Management Review, vol. 56, pp. 600-623, 2015.

[2] M. Tarafdar, A. Gupta, and O. Turel, "The dark side of information technology use," Information Systems Journal, vol. 23, pp. 269-275, May 2013.

[3] Q. He, O. Turel, and A. Bechara, "Brain anatomy alterations associated with Social Networking Site (SNS) addiction," Scientific Reports, vol. 7, pp. 1-8, 03/23/online 2017.

[4] Q. He, O. Turel, D. Brevers, and A. Bechara, "Excess social media use in normal populations is associated with amygdala-striatal but not with prefrontal morphology," Psychiatry Research-Neuroimaging, vol. 269, pp. 31-35, Nov 2017.

[5] O. Turel, A. Serenko, and P. Giles, "Integrating technology addiction and use: An empirical investigation of online auction sites," MIS Quarterly, vol. 35, pp. 1043-1061, Dec 2011.
[6] O. Gil-Or, Y. Levi-Belz, and O. Turel, "The "Facebook-self": Characteristics and psychological predictors of false self-presentation on Facebook," Frontiers in Psychology, vol. 6, 2015-February-17 2015.

[7] O. Turel, A. Serenko, and N. Bontis, "Family and work-related consequences of addiction to organizational pervasive technologies," Information \& Management, vol. 48, pp. 88-95, Mar 2011.

[8] O. Turel, A. Romashkin, and K. M. Morrison, "Health Outcomes of Information System Use Lifestyles among Adolescents: Videogame Addiction, Sleep Curtailment and Cardio-Metabolic Deficiencies," PLoS One, vol. 11, p. e0154764, 2016.

[9] O. Turel and A. Bechara, "Effects of motor impulsivity and sleep quality on swearing, interpersonally deviant and disadvantageous behaviors on online social networking sites," Personality and Individual Differences, vol. 108, pp. 91-97, 4/1/ 2017.

[10] O. Turel, "Organizational deviance via social networking site use: The roles of inhibition, stress and sex differences," Personality and Individual Differences, vol. 119, pp. 311-316, 12/1/ 2017.

[11] O. Turel and H. Qahri-Saremi, "Explaining unplanned online media behaviors: Dual system theory models of impulsive use and swearing on social networking sites," New Media \& Society, vol. forthcoming, p. $1461444817740755,2018$.

[12] O. Turel and A. Bechara, "Social Networking Site use while driving: ADHD and the mediating roles of stress, self-esteem and craving," Frontiers in Psychology, vol. 7, 2016.

[13] O. Turel, D. Brevers, and A. Bechara, "Time distortion when users at-risk for social media addiction engage in non-social media tasks," Journal of Psychiatric Research, vol. 97, pp. 84-88, 2// 2018. 